\title{
Сегментация и детекция структурных элементов колоса пшеницы
}

\author{
Заварзин Е. ${ }^{1 *}$, Приходько А. ${ }^{1}$, Прохошин Н. ${ }^{1}$, Комышев Е. ${ }^{2}$, Генаев M. ${ }^{1,2}$ \\ ${ }^{1}$ Новосибирский государственный университет, Новосибирск, Россия \\ ${ }^{2}$ Институт ичитологии и генетики СО РАН, Новосибирск, Россия \\ *e-mail: zavarzinevg@gmail.com
}

Ключевые слова: пшеница, колос, колоски, ости, феномика, компьютерное зрение, нейронные сети, сегментация, детекция

Мотивация и цель: Колос пшеницы — это сложное соцветие, для которого характерна удлиненная главная ось, на ней расположены сидячие одиночные колоски. Количество и тип посадки колосков определяют архитектонику колоса и влияют на многие показатели, в том числе на урожайность. Наличие остей - таксономический признак многих видов пшениц. При определении морфометрических признаков методами компьютерного зрения важным этапом является разделение колоса на области тела колоса и его ости. Цель работы: разработать метод компьютерного зрения для автоматической сегментации структурных элементов колоса пшеницы и детектирования отдельных колосков в колосе.

Meтоды и алгоритмы: Для решения задачи сегментации использовалась сверточная нейронная сеть архитектуры Unet [1] с энкодером resnet18 [2]. Разметка для обучения модели была получена автоматически на основе существующего алгоритма [3]. Для решения задачи детекции колосков обучалась модель, генерирующая бинарные маски колосков на основе обучающей выборки, где центры колосков аппроксимируются эллипсами. На основе этих масок производился поиск контуров колосков, подсчитывалось их количество, вычислялись их центры масс.

Результаты: Точность модели сегментации по метрике IoU составляет 0.90565 для тела колосса и 0.69115 для остей. Точность модели сегментации остей оказалась на $3 \%$ выше, чем у модели, представленной в статье [3]. Точность детекции колосков по метрике F1 составляет 0.9647.

Заключение: Для демонстрации работы предложенных моделей был разработан веб-сервис https://spikecv-demo.sysbio.ru. Пользователь может отправить свое изображение колоса или выбрать изображение из примеров. В результате будут предсказаны маски структурных элементов колоса, центры колосков и морфометрические характеристики колоса.

\section{Список литературы}

1. Zagoruyko S., Komodakis N. Wide residual networks. arXiv preprint arXiv:1605.07146. 2016.

2. Ronneberger O. et al. U-net: Convolutional networks for biomedical image segmentation. International Conference on Medical image computing and computer-assisted intervention. Springer, Cham, 2015;234-241.

3. Genaev M.A. et al. Morphometry of the Wheat Spike by Analyzing 2D Images. Agronomy. 2019, 9, 390. 